\title{
Lectures and the hidden curriculum
}

Paul Christine ${ }^{1} \&$ Matthew Rysavy ${ }^{2}$

Editor - We read with interest Dr Smith's recent commentary regarding lecture attendance in the pre-clinical curriculum. ${ }^{1}$ We agree that the first 2 years of medical school are formative and influence students' future professional behaviours. However, we submit that the issue of lecture attendance is attributable to far more than students' lifestyle preferences and involves the medium of lecture itself.

Criticism of the lecture as a teaching method existed long before students obtained the ability to watch lectures online. More than 200 years ago, Samuel Johnson wrote: 'Lectures were once useful; but now, when all can read and books are so numerous, lectures are unnecessary. ${ }^{2}$ In the 1950 s, the historian Henry Commager observed: 'Not only do we rely far too much on lectures, we rely on lectures to do far more than it is possible or desirable for them to do. ${ }^{3}$

Research has shown that although lectures may provide one-way transmission of information, they are no more effective than reading or independent study in this regard. ${ }^{4}$ Further, lectures are not

\footnotetext{
${ }^{1}$ Department of Epidemiology, University of Michigan Medical School and School of Public Health, Ann Arbor, Michigan, USA

${ }^{2}$ Department of Epidemiology, University of Iowa College of Medicine and College of Public Health, Iowa City, Iowa, USA

Correspondence: Paul Christine, Department of Epidemiology, University of Michigan Medical School and School of Public Health, 2675 SPH I, 1415 Washington Heights, Ann Arbor, Michigan 48109, USA.

Tel: 001734615 9209; Fax: 001734763

5706; E-mail: pjchris@umich.edu

doi: 10.1111/j.1365-2923.2012.04282.x
}

particularly useful for promoting critical thinking, teaching values, or fostering personal and social development; discussion, hands-on experiences and mentoring are more effective to these ends. ${ }^{4}$

So why do we continue to use lectures as a primary means of instruction in pre-clinical curricula? We understand the dilemma faced by medical schools that must educate many students in many subjects with limited resources and limited time. Tradition, infrastructure and institutional inertia may also bestow staying power to lectures.

However, we suggest that the metaphor of medical students as doctors shying from their compact with society to 'spend the first 2 years in bunny slippers" ${ }^{\text {' }}$ should be reconsidered. Rather, we might imagine lecturers as the doctors in this metaphor, prescribing an educational intervention that their noncompliant students have found to be ineffective. We ask: what is the hidden curriculum here?

We agree that a culture of noncompliance among future doctors is not desirable. As Dr Smith suggests, it will not produce the sense of duty or the readiness for team- work that society expects of our profession. However, the problem of lecture attendance is not the responsibility of students alone.

Several years before Samuel Johnson wrote about lectures, Adam Smith declared in the Wealth of Nations: 'No discipline is ever requisite to force attendance upon lectures which are really worth the attending, as is well known wherever any such lectures are given. ${ }^{5}$ In view of current trends in lecture attendance, we argue that an earnest re-evaluation of the appropriate use of lectures in medical schools is warranted.

\section{REFERENCES}

1 Smith LB. Medical school and online learning: does optional attendance create absentee doctors? Med Educ 2011;46:137-8.

2 Boswell J. The Life of Samuel Johnson, LLD. London: Printed for G Walker et al. 1820.

3 Commager HS. The problem isn't bricks - it's brains. New York Times Magazine, 19 January 1956.

4 Bligh DA. What's the Use of Lectures? 1st edn. San Francisco, CA: JosseyBass 2000:3-20.

5 Smith A. The Wealth of Nations, Part 3. New York, NY: Collier 1902:142. 